\title{
Dynamics of chromosomal evolution in the genus Hypsiboas (Anura: Hylidae)
}

\author{
M.A. Carvalho ${ }^{1}$, M.T. Rodrigues ${ }^{2}$, S. Siqueira ${ }^{1}$ and C. Garcia ${ }^{1}$ \\ ${ }^{1}$ Laboratório de Citogenética, Departamento de Ciências Biológicas, \\ Universidade Estadual do Sudoeste da Bahia, Jequié, BA, Brasil \\ ${ }^{2}$ Departamento de Zoologia, Instituto de Biociências, \\ Universidade de São Paulo, São Paulo, SP, Brasil
}

Corresponding author: M.A. Carvalho

E-mail: peuamorim@gmail.com

Genet. Mol. Res. 13 (3): 7826-7838 (2014)

Received August 2, 2013

Accepted January 10, 2014

Published September 26, 2014

DOI http://dx.doi.org/10.4238/2014.September.26.21

\begin{abstract}
Hylidae is one of the most species-rich families of anurans, and $40 \%$ of representatives in this group occur in Brazil. In spite of such remarkable diversity, little is known about this family and its taxonomical and systematic features. Most hylids have $2 \mathrm{n}=$ 24 , even though most of the cytogenetic data are mainly obtained based on the conventional chromosomal staining and are available for only $16 \%$ of Hypsiboas species, a genus accounting for about $10 \%$ of the hylid diversity. In this study, cytogenetic data of distinct species and populations of Hypsiboas were analyzed, and the evolutionary dynamics of chromosomal macro- and microstructure of these amphibians were discussed. Contrary to the conservativeness of $2 \mathrm{n}$ $=24$, this genus is characterized by a high variation of chromosomal morphology with as much as 8 karyotype patterns. Differences in the number and location of nucleolus organizer regions and C-bands allowed the identification of geographical variants within nominal
\end{abstract}


species and cytotaxonomical chromosomal markers. Comparative analyses revealed a strong phylogeographic relationship between chromosomal patterns in this group.

Key words: Ag-NORs; C-banding; Chromosomes; Karyotype evolution; Pericentric inversion

\section{INTRODUCTION}

Hylidae is recognized as one of the most species-rich families in the order Anura. These amphibians are mainly distinguished by the presence of adhesive disks in their fingers and by their arboreal behavior; they are found in all continents except Antarctica, with predominance over the Neotropical region (Frost, 2012).

Hylids comprise 47 genera and 907 species (Amphibiaweb, 2012), commonly subdivided into 3 subfamilies: Phyllomedusinae, Pelodryadinae, and Hylinae (Faivovich et al., 2005; Wiens et al., 2010). Among these, the subfamily Hylinae is the most diverse one, encompassing about 650 species (Frost, 2012).

The species richness and wide geographical range account for the controversial taxonomy and systematics of Hylinae. Therefore, phylogenetic studies have focused on this subfamily to verify their monophyletism and the taxonomic validation of their members (Faivovich et al., 2005; Salducci et al., 2005; Wiens et al., 2010). One of the groundbreaking studies using this approach was carried out by Faivovich et al. (2005); they revealed a remarkable change in taxonomic relationships of Hylinae. On the basis of sequencing data of mitochondrial and nuclear genes as well as morphological data of 226 Hylidae species, these authors reallocated two-third of the species formerly recognized in the genus Hyla into other 15 genera, including Hypsiboas.

Members of the genus Hypsiboas are popularly known as tree frogs and widespread throughout humid areas of Atlantic Forest, Amazon, Brazilian savannah, and Caatinga; this genus includes 86 species, accounting for about $10 \%$ of the total hylid diversity (Amphibiaweb, 2012). According to genetic, morphological, behavioral, and ecological data, Hypsiboas frogs are divided into 7 species groups: Hypsiboas albopunctatus, Hypsiboas benitezi, Hypsiboas faber, Hypsiboas pellucens, Hypsiboas pulchellus, Hypsiboas punctatus, and Hypsiboas semilineatus (Faivovich et al., 2005).

Such groupings are supported by morphological synapomorphies that are useful to define monophyletic units. However, some species have characters that hinder their allocation in any of the currently recognized groups (Faivovich et al., 2005).

Recently, Wiens et al. (2010) identified 7 monophyletic groups in this family by gene sequencing; however, their evolutionary relationships were slightly divergent from those proposed by Faivovich et al. (2005).

Despite the continuous efforts to clarify the systematic relationships in Hylidae, few karyotypic reports are available. Less than $17 \%$ of anurans have been cytogenetically analyzed, and most of these studies are restricted to karyotype macrostructure determined using conventional staining techniques (King, 1990).

For several years, amphibians have been regarded as one of the few vertebrate groups characterized by highly conserved karyotypes. Nonetheless, with improvements in 
the methods of chromosomal banding and molecular cytogenetics, a remarkable variability in chromosomal microstructure has been reported, which allowed a refined identification of species and their geographical variants, thereby serving as a reliable tool for taxonomic studies (Kasahara et al., 2003; Siqueira et al., 2004).

Usually, hylids have $2 \mathrm{n}=24$, with a karyotype that mainly consists of biarmed chromosomes (King, 1990), and variations in chromosomal number have been regarded as apomorphies (Catroli, 2008). One exception is the genus Dendropsophus, separated from the genus Hyla to comprise species with 30 chromosomes despite their incipient morphological diagnosis, thus showing the importance of cytogenetics to analyze systematics in this group (Chek et al., 2001).

Within Hypsiboas, cytogenetic data have been shown for only $16 \%$ of the species, most of which have been derived based on conventional karyotype descriptions, and thus, some inferences about their chromosomal evolution that need to be determined using banding techniques are missing (Raber et al., 2004; Ananias et al., 2004; Gruber et al., 2006; Nunes and Fagundes, 2008; Carvalho et al., 2009).

The present study aimed to perform a thorough cytogenetic analysis in distinct species of Hypsiboas and compare these data to those obtained in previous studies in order to identify chromosomal markers that could be used to outline the evolutionary dynamics of chromosomal macro- and microstructure of these amphibians.

\section{MATERIAL AND METHODS}

Cytogenetic analyses were performed in specimens of Hypsiboas crepitans, Hypsiboas pombali, and H. semilineatus from Estação Ecológica Estadual Wenceslau Guimarães (EEEWG; municipality of Wenceslau Guimarães) and Hypsiboas atlanticus from an Atlantic forest fragment in the municipality of Itacaré; both sites are located in Bahia state, northeastern Brazil (Figure 1). Voucher specimens are deposited in the Cytogenetics Laboratory at Universidade Estadual do Sudoeste da Bahia and Museu de Zoologia, Universidade de São Paulo. Besides the data obtained in the present study, those obtained in previous studies in other Hypsiboas species and populations were also analyzed.

Mitotic chromosomes were obtained from the intestinal epithelium as described by King and Rofe (1976) with modifications (hypotonic treatment in distilled water for $20 \mathrm{~min}$, followed by fixation in 3:1 Carnoy's solution for $24 \mathrm{~h}$ ) or else by dissociation of liver tissue according to Garcia C. (unpublished data).

Chromosomal number and morphology were determined using conventional Giemsa staining, and the number of chromosomal arms (FN) was established taking into account that metacentric, submetacentric, and subtelocentric chromosomes bear 2 arms and acrocentric chromosomes are one-armed.

Idiograms were constructed on the basis of the results obtained in this study as well as those reported previously. Each karyotype figure was digitalized, and chromosomes were digitally measured according to Levan et al. (1964). The chromosomal measurements were used to build the idiograms. This standardization of chromosomal morphology pattern was required to allow a reliable comparison of distinct karyotype formulae and sizes, since different authors follow different criteria of chromosomal classification.

C-banding was performed according to Sumner (1972) with modifications. The 
slides were initially immersed in 3:1 Carmoy's fixative for $10 \mathrm{~min}$ and then treated with 0.2 $\mathrm{N} \mathrm{HCl}$ for $13 \mathrm{~min}$ at room temperature. Subsequently, the slides were immersed in $\mathrm{Ba}(\mathrm{OH})_{2}$ solution at $60^{\circ} \mathrm{C}$ for $60 \mathrm{~s}$, followed by incubation in a $2 \mathrm{X}$ standard saline citrate bath at $60^{\circ} \mathrm{C}$ for $30 \mathrm{~min}$. Finally, the slides were stained with $5 \%$ Giemsa solution in phosphate buffer $(\mathrm{pH} 6.8)$.

Active nucleolus organizer regions (Ag-NORs) were detected using silver nitrate staining as proposed by Howell and Black (1980).

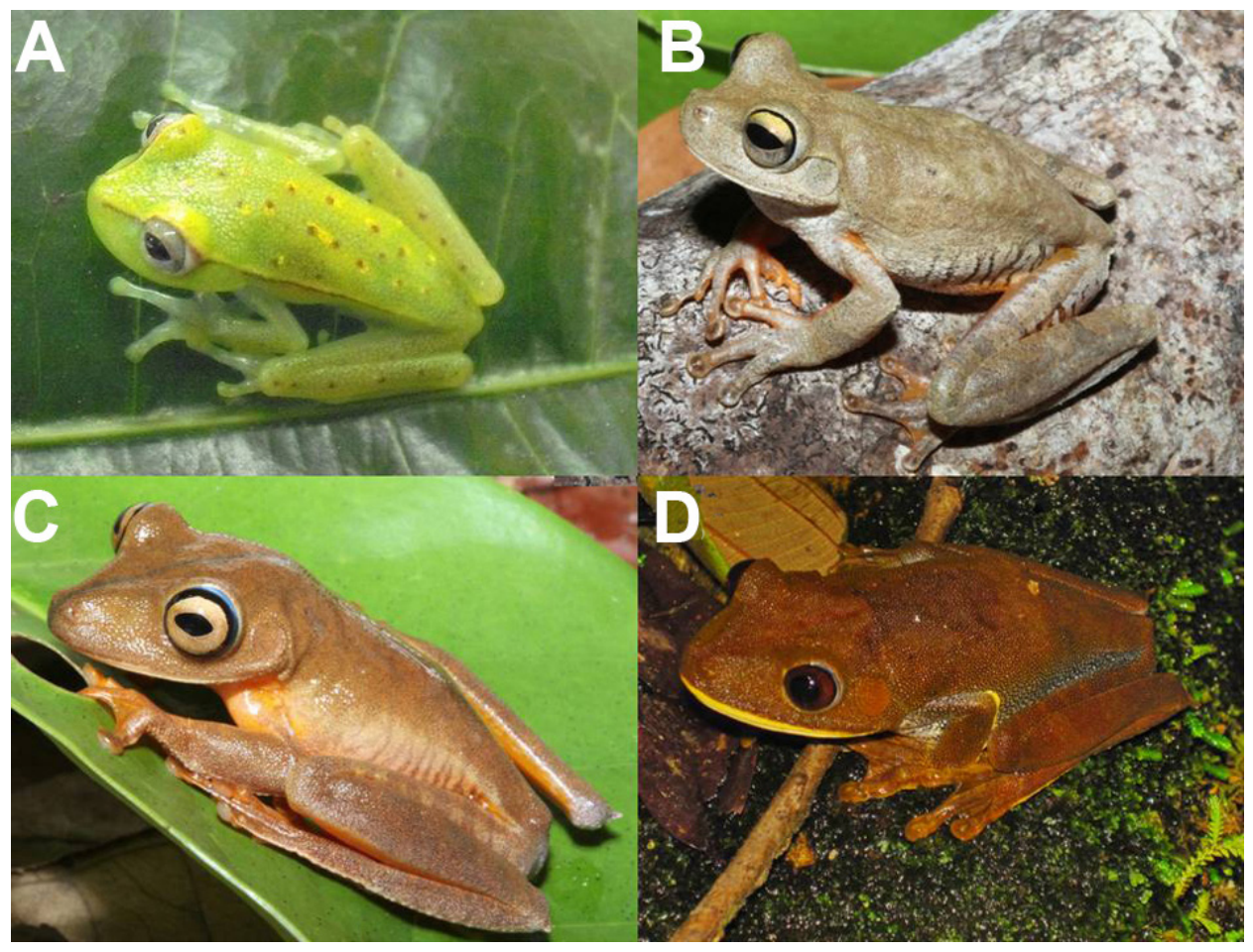

Figure 1. Photographs of individuals of Hypsiboas species analyzed in this study: A. H. atlanticus. B. H. crepitans. C. H. pombali. D. H. semilineatus. Photos by: Sérgio Siqueira Jr (A) and Mauro Teixeira Jr (B, C, D).

\section{RESULTS}

All species of Hypsiboas analyzed in this study had $2 \mathrm{n}=24$ and $\mathrm{FN}=48$, with distinct karyotype formulae (Figure 2, Tables 1 and 2).

Single Ag-NORs were identified at interstitial position on long arms of the seventh chromosomal pair in $H$. crepitans, $H$. pombali, and H. semilineatus. All silver-stained metaphases in $H$. pombali and $H$. semilineatus showed Ag-NOR marks on only 1 homologous chromosome from such a pair. $H$. atlanticus presented multiple and terminal NORs on long arms of 2 chromosomal pairs (10 and 12; Figure 2, boxes). 
C-banding revealed heterochromatin blocks near centromeres in all chromosomes of $H$. crepitans, $H$. semilineatus, and $H$. pombali, as well as in pairs 1-5 of $H$. atlanticus. Additional C-bands were observed at subterminal and interstitial positions on long arms of pairs 1 , $2,3,6,7$, and 8 of $H$. atlanticus and on the short arms of pair 3 in H. crepitans. Terminal heterochromatin segments coincident to NORs were detected only in $H$. atlanticus. In the other species, the Ag-NORs proved to be euchromatic (Figures 2 and 3).

The association of present data with the available cytogenetic reports in Hypsiboas assured a detailed comparison of karyotypic formulae in these amphibians (Table 1). After the chromosomal measurements were standardized, 8 karyotype groups could be defined, many of which were shared by distinct species (Table 2 and Figure 3).

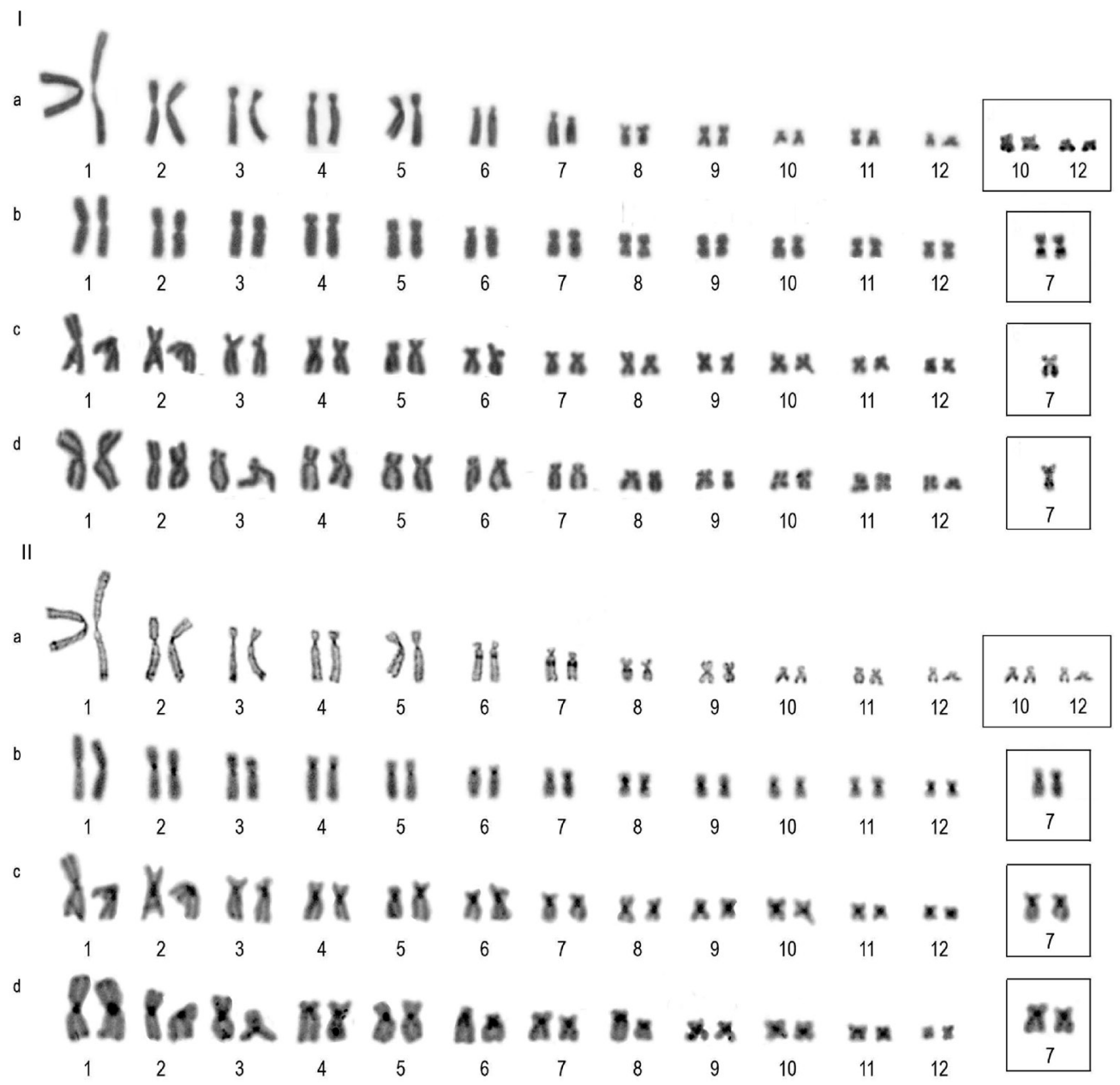

Figure 2. Giemsa stained (I) and C-banded (II) karyotypes of: a. H. atlanticus; b. H. crepitans; c. H. pombali, and d. H. semilineatus. In boxes, the NOR-bearing chromosomes after silver nitrate staining and C-banding. 


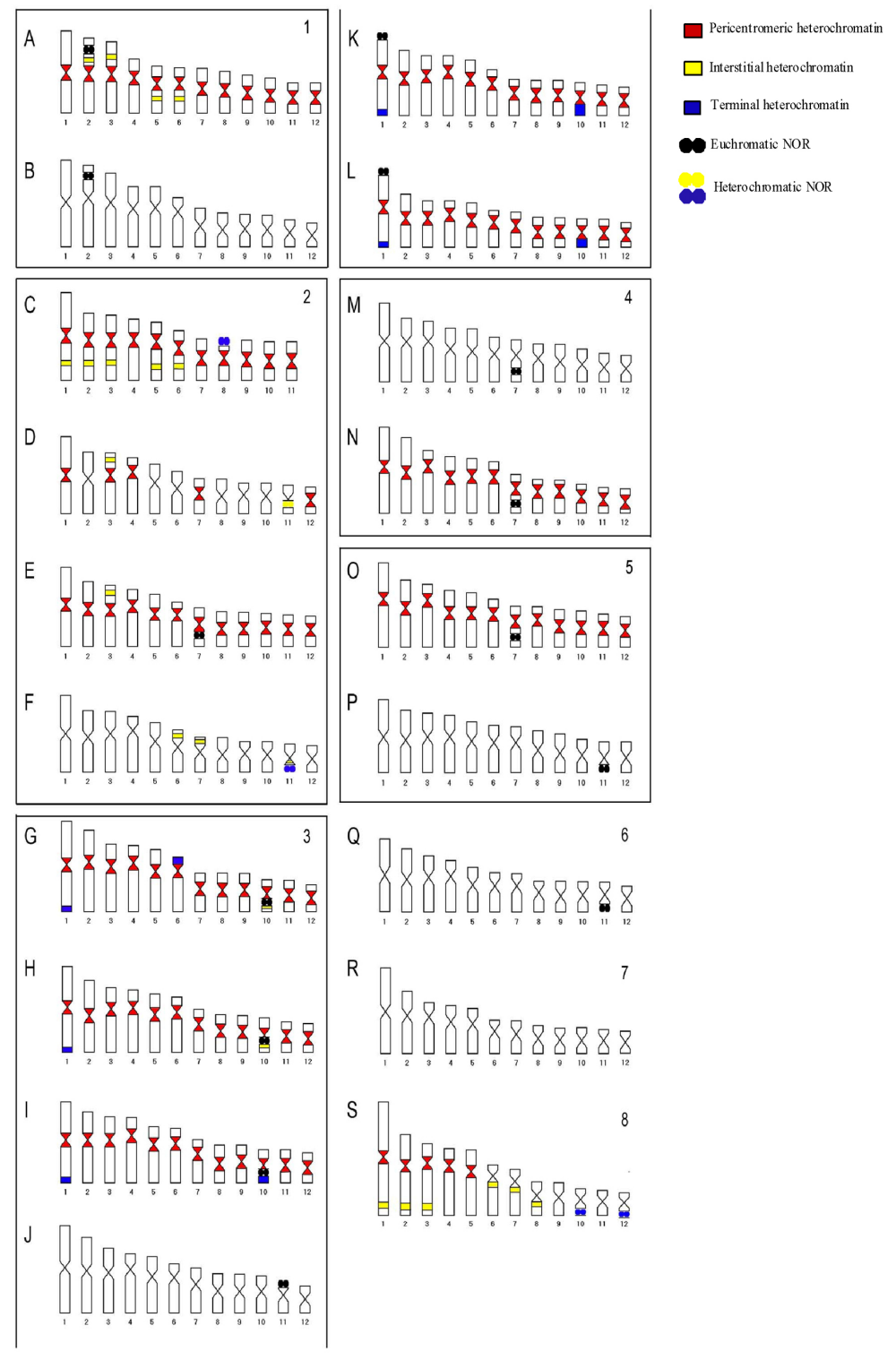

Figure 3. Idiograms of cytogenetically analyzed Hypsiboas species. A. H. albomarginatus (Carvalho et al., 2009); B. H. albomarginatus (Nunes and Fagundes, 2008); C. H. albopunctatus (Gruber et al., 2006); D. H. crepitans (Gruber et al., 2006); E. H. crepitans (present study); F. H. raniceps (Gruber et al., 2006); G. H. bischoffi (Raber et al., 2004); H. H. guentheri (Raber et al., 2004); I. H. marginatus (Ananias et al., 2004); J. H. pardalis (Nunes and Fagundes, 2008); K. H. semiguttatus (Ananias et al., 2004); L. H. sp aff semiguttatus (Ananias et al., 2004); M. H. semilineatus (Nunes and Fagundes, 2008); N. H. semilineatus (present study); O. H. pombali (present study); P. H. faber (Carvalho et al., 2009); Q. H. faber (Nunes and Fagundes, 2008); R. H. polytaenius (Nunes and Fagundes, 2008); S. H. atlanticus (present study). 
M.A. Carvalho et al.

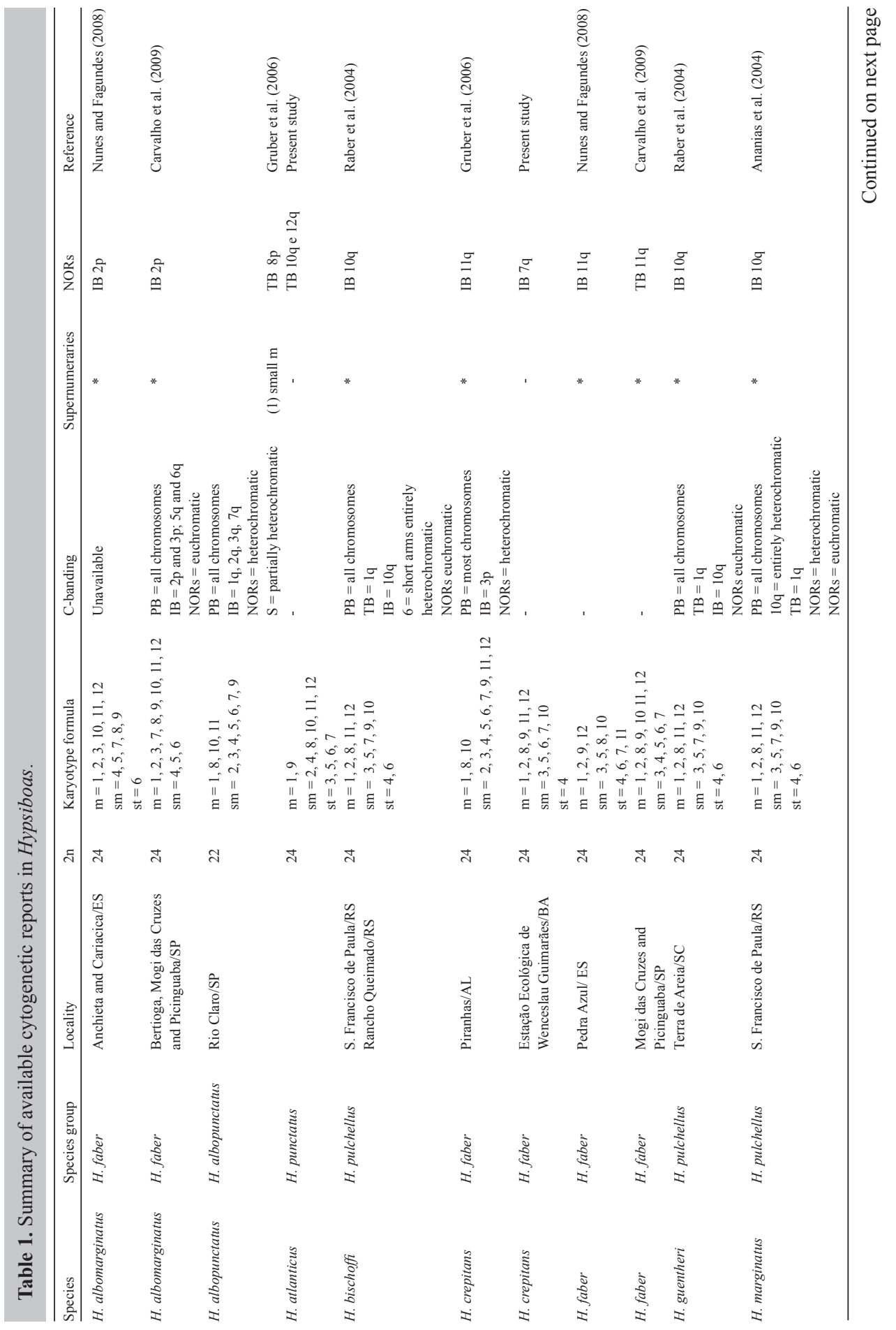


Dynamics of chromosomal evolution in the genus Hypsiboas

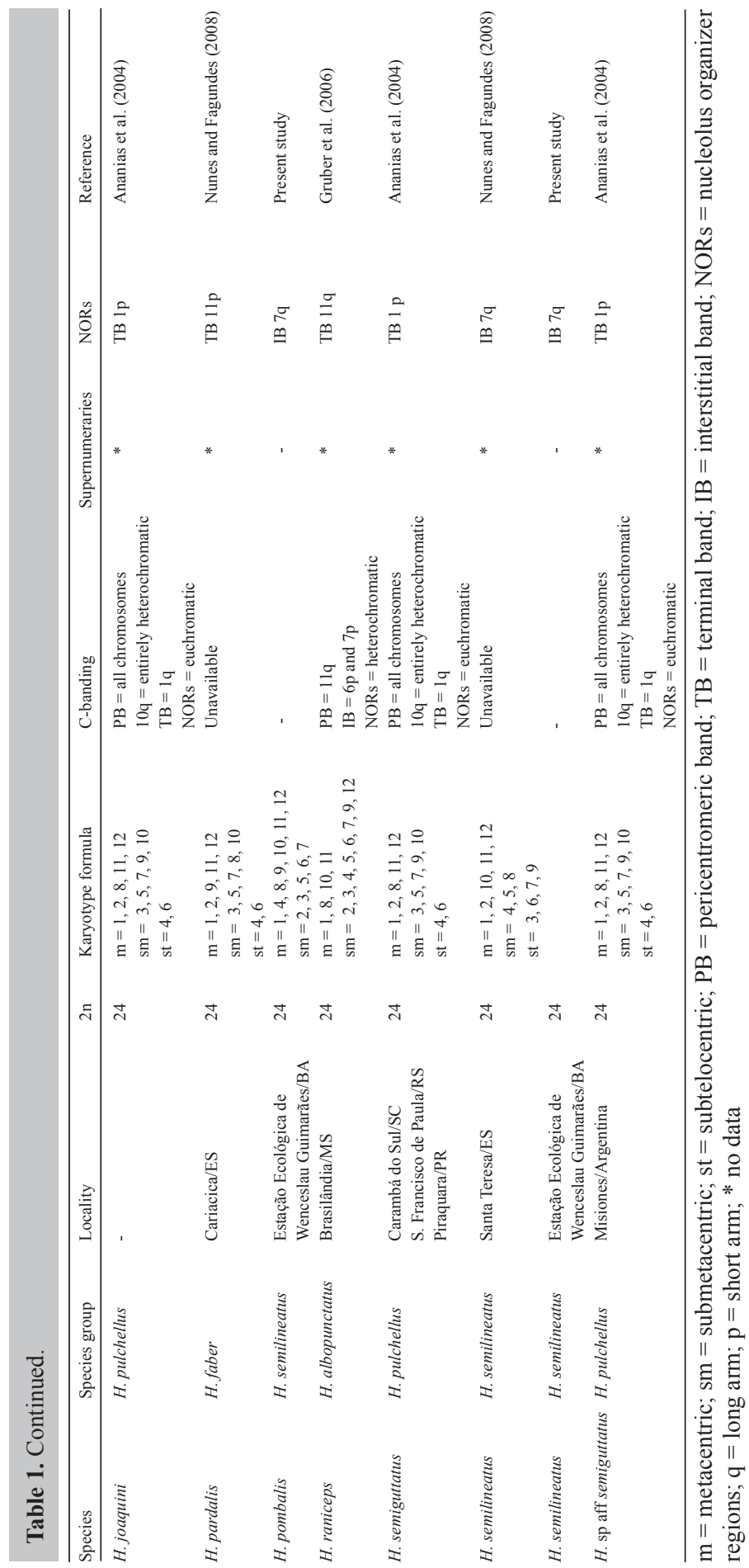


Table 2. Karyotype formulae in species of Hypsiboas after standardization of chromosomal measurements.

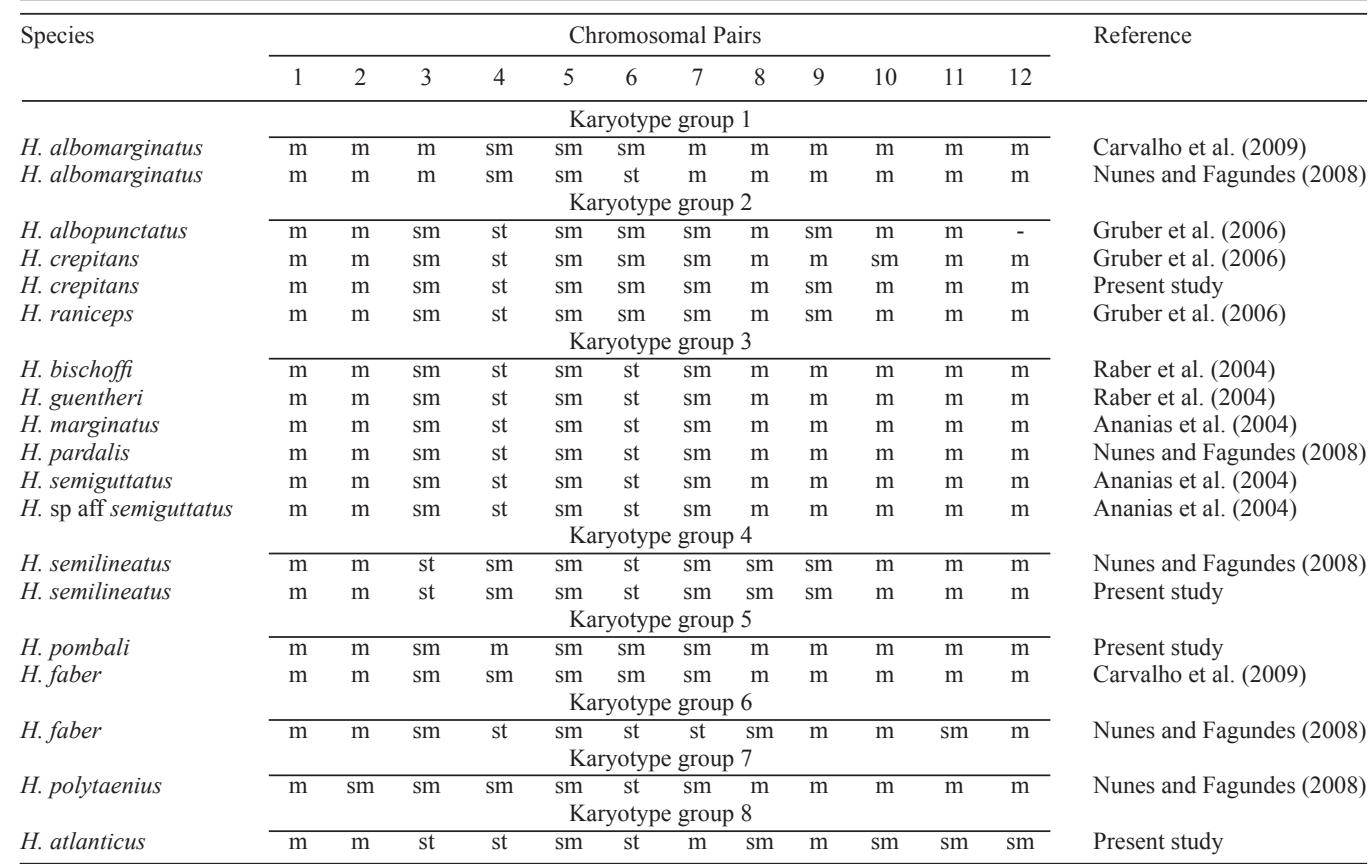

$\mathrm{m}=$ metacentric; $\mathrm{sm}=$ submetacentric; $\mathrm{st}=$ subtelocentric.

With regard to the karyotype macrostructure, only chromosomal pairs 1 and 5 (metacentric and submetacentric, respectively) remained unchanged in all species analyzed thus far. The remaining chromosomal pairs were characterized by variations in centromere position, although pairs 2, 10, 11, and 12 were less variable in morphology (Table 2).

Comparison of the distribution pattern of constitutive heterochromatin and Ag-NORs revealed that some chromosomal markers could be identified in Hypsiboas albomarginatus (interstitial NORs on short arms of pair 2), H. crepitans (interstitial and subterminal heterochromatin on short arms of pair 3), and in species of the H. pulchellus group (terminal heterochromatin on long arms of pair 1; Figure 3).

\section{DISCUSSION}

Of the 86 species recognized of the genus Hypsiboas, only 15 have been cytogenetically analyzed, including those analyzed in the present data. All species share $2 \mathrm{n}=24$ chromosomes and $\mathrm{FN}=48$, except $H$. albopunctatus $(2 \mathrm{n}=22$; Table 1$)$. The predominance of a diploid number of 24 chromosomes is one of the main cytogenetic features within Hylidae, even though higher and lower diploid values have already been reported $(2 \mathrm{n}=18$ in Aplastodiscus leucopygius up to $2 \mathrm{n}=52$ in Phyllomedusa tretraploidea; Catroli, 2008). The karyotype consisting of 24 chromosomes or lower diploid values present in derived anuran families such as Dendrobatidae, Hylidae, Leptodactylidae, and Ranidae have been thought to have evolved through numerical reduction from a putative ancestor with $2 n=26$ (Bogart, 1973), as 
corroborated by the phylogeny proposed by Faivovich et al. (2005).

According to Gruber et al. (2006), 2 mechanisms could account for the reduction in the diploid number of $H$. albopunctatus: tandem fusions or translocations between the smallest chromosomes that also likely resulted in the differential NOR position. These authors have also argued that the occurrence of a supernumerary chromosome reported in this species could be indicative of the former presence of 24 chromosomes in $H$. albopunctatus.

As for chromosomal morphology, the karyotypes of Hypsiboas mainly consist of several pairs of biarmed chromosomes that are thought to have evolved dynamically. While both morphology and size of pairs 1 and 5 remain constant in all species/populations studied, pairs $3,4,6$, and 7 are morphologically variable between samples ranging from metacentric and submetacentric to subtelocentric (Table 2). This behavior, coupled with the size maintenance of chromosomal pairs, is strong evidence that pericentric inversions are the main mechanism responsible for the differentiation of the karyotype macrostructure in this group.

On the basis of such chromosomal macrostructure, we clustered the species and/or populations analyzed into 8 groups, distinguished by their karyotype formulae (herein called karyotype groups; Figure 3 and Table 2). These karyotype groups were not composed of populations from a single species or species from the same group established by Faivovich et al. (2005) and Wiens et al. (2010). For instance, in the H. faber species group, 5 karyotype formulae were identified (karyotype groups 1, 2, 3, 5, and 6). Similarly, H. semilineatus and $\mathrm{H}$. pulchellus showed 2 karyotype groups each (karyotype groups 4-5 and 3-7, respectively). On the other hand, the groups $H$. albopunctatus and $H$. punctatus comprised a single chromosomal pattern (karyotype groups 2 and 8, respectively). Thus, in spite of sharing a similar karyotype pattern, the chromosomal microstructure within Hypsiboas was highly variable and could be used to differentiate species and their geographical variants.

In general, NORs are a useful cytogenetic marker in amphibians, and the number and location of these sites remain constant within most species of anurans (Lourenço et al., 1998).

On the other hand, NORs in species and populations of Hypsiboas are variable, although most species presented single NORs located interstitially on long arms of mediumsized to small chromosomes (pairs 7, 10, and 11; present study; Ananias et al., 2004; Gruber et al., 2006; Nunes and Fagundes, 2008). Besides interspecific variation, 2 populations of $H$. crepitans (present study; Gruber et al., 2006) also differed in relation to the NOR-bearing pair. These data indicate that NORs are weak chromosomal markers for species identification of the genus Hypsiboas when used separately from other techniques or, alternatively, they might indicate the presence of cryptic species. Nonetheless, NORs located on the largest chromosomes (pairs 1 and 2) or terminal NORs were restricted to certain groups, serving as species-specific markers, such as in H. albomarginatus and Hypsiboas semiguttatus (Ananias et al., 2004; Nunes and Fagundes, 2008).

To our knowledge, this is the first report of multiple NORs in H. atlanticus, unlike the predominance of terminal single NORs in anurans (King et al., 1990). The available phylogenetic studies in Hypsiboas suggest that interstitial single NORs are likely a plesiomorphic trait (Nunes and Fagundes, 2008), while variant conditions would be apomorphic.

The variability in NOR location could be explained by translocation or transposition events; both the number and size of chromosomes remain unchanged among the distinct karyotypes analyzed. Similar mechanisms can be inferred to determine the multiple NORs in H. atlanticus. Putatively, the ancestor species would bear terminal NORs on pair 10. A portion 
of rDNA sites would have been transferred to the terminal region of pair 12 via translocation or transposition, resulting in the small silver-stained signals observed in this species. Likewise, transposition and/or translocation events have been regarded as the main mechanisms of dispersal of 45S ribosomal sites in anurans with multiple NORs (Schmid et al., 1995).

The application of fluorescent in situ hybridization (FISH) using $45 \mathrm{~S}$ rDNA performed in 4 Hypsiboas species (H. albomarginatus, H. faber, Hypsiboas pardalis, and H. semilineatus) invariably confirmed the occurrence of single NORs (Nunes and Fagundes, 2008). This technique would be very useful in the present study to corroborate this pattern once a single homologous chromosome was stained with silver nitrate in both $\mathrm{H}$. pombali and $\mathrm{H}$. semilinea$t u s$, indicating preferential activation of ribosomal sites in the preceding interphase. Moreover, FISH could be useful to verify the actual occurrence of multiple NORs in H. atlanticus, since there are reports of intraspecific silver-stained regions equivalent to heterochromatin segments with acidic nature in other animal groups (Sumner, 1990; Sánchez et al., 1995).

Heterochromatin distribution is one of the main features used in chromosomal differentiation between species or populations of anurans. Thus, these regions represent one of the most widely used chromosomal markers in cytotaxonomic studies of species within the genera Hyla (Anderson, 1991), Telmatobufo (Formas and Cuevas, 2000), and Allobates (VeigaMenoncello et al., 2003).

The few available reports in Hypsiboas show that most species present large blocks of pericentromeric heterochromatin through the karyotype. Interstitial C-bands are observed in some chromosomes of a few species, and terminal blocks are even less frequent (Table 1 and Figure 2). However, a thorough comparison of the pattern of heterochromatin distribution among populations is hindered because most reports lack C-banding data.

The evolutionary relationships of the species studied in the molecular phyaslogeny established by Faivovich et al. (2005) and the data compiled in Figure 3, as well as those from closely related species, suggest that the karyotypes exclusively comprising pericentromeric heterochromatin should reflect a plesiomorphic feature in this group. Therefore, interstitial or terminal heterochromatic blocks would be considered variation of the ancestral condition.

The species of Hypsiboas with interstitial/terminal heterochromatin are known to present reduced amounts of pericentromeric blocks, as observed in $H$. albomarginatus, $H$. albopunctatus, H. crepitans, Hypsiboas raniceps, and H. atlanticus (Gruber et al., 2006, Carvalho et al., 2009; present study). This association can be the result of chromosomal inversions that determined the transference of heterochromatic regions to chromosomal arms, thereby changing the pair morphology and reinforcing that inversions are the main mechanism of karyotype evolution in Hypsiboas. Such inversions, involving heterochromatic segments, could also account for the existence of some species with heterochromatic NORs, while most of the species present euchromatic NORs. These regions possibly became interspersed or associated with heterochromatic after the occurrence of such structural reorganization of chromosomes.

The interstitial heterochromatin in pair 3 of $H$. crepitans can be a potential speciesspecific marker, since it is observed only in populations of this species and is conserved throughout geographical variants. A similar situation is found in relation to the C-terminal band on the long arms of pair 1 in species from the group $H$. pulchellus and for the terminal block on the short arms of pair 6 in Hypsiboas bischoffi (Figure 3).

The pattern of heterochromatin and NOR distribution among populations of a single species or closely related species is thought to be similar. However, according to the data 
shown in figure 3 and the collection sites of populations analyzed, we can infer that the evolution of karyotype microstructure is related to geography than to phylogenetic relationships. For instance, the species studied from EEEWG shared the same C-banding and Ag-NOR pattern despite the differences in the karyotype formulae. This pattern was also reported for Hypsiboas marginatus, $H$. semiguttatus, and $H$. aff. semiguttatus (Ananias et al., 2004) and for $H$. bischoffi and Hypsiboas guentheri (Raber et al., 2004). This relationship between evolutionary dynamics of chromosomal microstructure and geographic location could be determined by unique environmental features that favored an optimal karyotype organization. Similar inferences have been proposed to explain geographical variation in lizards of the genus Tropidurus (Kasahara et al., 1996) and some fish groups, such as Leporinus (Galetti Jr et al., 1981, 1984). Nonetheless, this hypothesis can only be confirmed with increased cytogenetic studies in the genus Hypsiboas.

Our data suggest that Hypsiboas represents an interesting model to study chromosomal evolution in anurans, because this genus presents a remarkable karyotype variation, although most of its diversity remains unexplored karyologically. The identification of cytotaxonomic markers and the putative phylogeographic relationships in the karyotype microstructure indicate that further chromosomal studies are required in this genus. Due to taxonomical controversy of this frog group, population studies using cytogenetic and molecular techniques should also be performed to identify the cryptic diversity in some species, such as those detected in $H$. crepitans and $H$. faber.

\section{ACKNOWLEDGMENTS}

The authors are grateful to Mauro Teixeira Júnior, Renato Recoder, and Francisco Dal Vechio for the collection and identification of specimens; Mauro Teixeira Júnior for obtaining the photographs of the species; Prof. Dr. Mirco Solé for the identification of Hypsiboas atlanticus; and the staff at Estação Ecológica Estadual Wenceslau Guimarães, especially, Mr. Rogério Miranda Ribeiro, for assistance during field trips. Research supported by Fundação de Amparo à Pesquisa do Estado da Bahia (FAPESB; \#BOL 1399/2010), Fundação de Amparo à Pesquisa do Estado de São Paulo (FAPESP), Conselho de Aperfeiçoamento do Ensino Superior (CAPES), and Conselho Nacional de Desenvolvimento Científico e Tecnológico (CNPq).

\section{REFERENCES}

Amphibiaweb (2012). Available at [http://www.amphibiaweb.org]. Accessed March 2, 2012.

Ananias F, Garcia PC and Recco-Pimentel SM (2004). Conserved karyotypes in the Hyla pulchella species group (Anura, Hylidae). Hereditas 140: 42-48.

Anderson K (1991). Chromosome Evolution in Holartic Treefrogs. In: Amphibians Cytogenetics and Evolution (Green DM and Sessions SK, eds.). Academic Press, New York, 299-331.

Bogart JP (1973). Evolution of Anuran Karyotypes. In: Evolutionary Biology of the Anurans: Contemporary Research on Major Problems (Vial JL, ed.). University of Missuru Press, Columbia, 337-349.

Carvalho KA, Garcia PC and Recco-Pimentel SM (2009). Cytogenetic comparison of tree frogs of the genus Aplastodiscus and the Hypsiboas faber group (Anura, Hylidae). Genet. Mol. Res. 8: 1498-1508.

Catroli GF (2008). Cariótipo de seis espécies de Bokermannohyla dos grupos de B. circumdata e B. pseudopseudis (Anura, Hylidae). Master's thesis. Instituto de Biociências, Universidade Estadual Paulista, Rio Claro.

Chek AA, Lougheed S, Bogart JP and Boag PT (2001). Perception and history: molecular phylogeny of a diverse group of neotropical frogs, the 30-chromosome Hyla (Anura: Hylidae). Mol. Phyl. Evol. 18: 370-385. 
Faivovich J, Haddad CFB, Garcia PCA, Frost DR, et al. (2005). Systematic review of the frog family Hylidae, with special reference to Hylinae: phylogenetic analysis and taxonomic revision. Bull. Am. Museum Nat. Hist. 294: 1-240. 294: $1-240$.

Formas JR and Cuevas CC (2000). Comparative cytogenetic analysis of the Chilean leptodactylid frog genus Telmatobufo, with the description of the chromosomes of T. venustus. Proc. Biol. Soc. Wash. 113: 890-899.

Frost DR (2012). Amphibian Species of the World: An Online Reference, version 5.3. Available at [http://research.amnh. org/herpetology/amphibia]. Accessed February 26, 2012.

Galetti PM Jr, Foresti F, Bertollo LAC and Moreira-Filho O (1981). Karyotypic similarity in three genera (Leporinus, Leporellus and Schizodon) of the family Anostomidae (Teleostei). Braz. J. Genet. 4: 11-15.

Galetti PM Jr, Foresti F, Bertollo LAC and Moreira-Filho O (1984). Characterization of eight species of Anostomidae fish on the basis of the nucleolar organizing regions. Caryologia 37: 401-406.

Gruber SL, Haddad CF and Kasahara S (2006). Chromosome banding in three species of Hypsiboas (Hylidae, Hylinae), with special reference to a new case of B-chromosome in anuran frogs and to the reduction of the diploid number of $2 \mathrm{n}=24$ to $2 \mathrm{n}=22$ in the genus. Genetica 130: 281-291.

Howell WM and Black DA (1980). Controlled silver-staining of nucleolus organizer regions with a protective colloidal developer: a 1-step method. Experientia 36: 1014-1015.

Kasahara S, Pellegrino KCM, Rodrigues MT and Yassuda YY (1996). Comparative cytogenetic studies of eleven species of the Tropidurus torquatus group (Sauria, Tropiduridae) with banding patterns. Hereditas 125: 37-46.

Kasahara S, Zampieri Silva AP, Gruber SL and Haddad CF (2003). Comparative cytogenetic analysis on four tree frog species (Anura, Hylidae, Hylinae) from Brazil. Cytogenet. Genome Res. 103: 155-162.

King M (1990). Amphibia. In: Animal Cytogenetics. Amphibia 4 Chordata 2 (John B and Gwent C, eds.). Gebruder Borntraeger, Berlin, 1-241.

King M and Rofe R (1976). Karyotypic variation in the Australian gekko Phyllodactylus marmoratus (Gray) (Gekkonidae: Reptilia). Chromosoma 54: 75-87.

Levan A, Fredga K and Sandberg AA (1964). Nomenclature for centromeric position on chromosomes. Hereditas 52: 201-220.

Lourenço LB, Recco-Pimentel SM and Cardoso AJ (1998). Polymorphism of the nucleolus organizer regions (NORs) in Physalaemus petersi (Amphibia, Anura, Leptodactylidae) detected by silver staining and fluorescence in situ hybridization. Chromosome Res. 6: 621-628.

Nunes RRA and Fagundes V (2008). Patterns of ribosomal DNA distribution in hylid frogs from the Hypsiboas faber and H. semilineatus species groups. Genet. Mol. Biol. 31: 982-987.

Raber SC, Carvalho KA, Garcia PC, Vinciprova G, et al. (2004). Chromosomal characterization of Hyla bischoffi and Hyla guentheri (Anura, Hylidae). Phyllomedusa 3: 43-49.

Salducci MD, Marty C, Fouquet A and Gilles A (2005). Phylogenetic relationships and biodiversity in hylids (Anura: Hylidae) from French Guiana. C R Biol. 328: 1009-1024.

Sánchez A, Jimenez R, Burgos M, Stitou S, et al. (1995). Cytogenetic peculiarities in the Algerian hedgehog: silver stains not only NORs but also heterochromatic blocks. Heredity 75 ( Pt 1): 10-16.

Schmid M, Feichtinger W, Weimer R, Mais C, et al. (1995). Chromosome banding in Amphibia. XXI. Inversion polymorphism and multiple nucleolus organizer regions in Agalychnis callidryas (Anura, Hylidae). Cytogenet. Cell Genet. 69: 18-26.

Siqueira S, Ananias F and Recco-Pimentel SM (2004). Cytogenetic analysis of three species of Eleutherodactylus (Anura, Leptodactylidae) from southeastern Brazil. Genet. Mol. Biol. 27: 363-372.

Sumner AT (1972). A simple technique for demonstrating centromeric heterochromatin. Exp. Cell Res. 75: 304-306.

Sumner AT (1990). Chromosome Banding. Uniwin Hyman, Londres.

Veiga-Menoncello AC, Lima AP and Recco-Pimentel SM (2003). Cytogenetic analysis of four central Amazonian species of Colostethus (Anura - Dendrobatidae) with a diploid complement of 22 chromosomes. Hereditas 139: 189-198.

Wiens JJ, Kuczynski CA, Hua X and Moen DS (2010). An expanded phylogeny of treefrogs (Hylidae) based on nuclear and mitochondrial sequence data. Mol. Phylogenet. Evol. 55: 871-882. 